East African Medical Journal Vol. 80 No. 4 April 2003

PREVALENCE AND RISK FACTORS OF SMOKING AMONG SECONDARY SCHOOL STUDENTS IN NAIROBI

D.H.O. Kwamanga, MSc, Principal Research Officer, J.A. Odhiambo, MD, Director, Centre for Respiratory Disease Research, Principal Research Officer and E.I. Amukoye, MD, Senior Research Officer, Centre for Respiratory Diseases Research, Kenya Medical Research Institute, P.O. Box 47855, Nairobi, Kenya

Request for reprints to: Mr. D.H.O. Kwamanga, Centre for Respiratory Diseases Research, Kenya Medical Research Institute, P.O. Box 47855, Nairobi, Kenya

\title{
PREVALENCE AND RISK FACTORS OF SMOKING AMONG SECONDARY SCHOOL STUDENTS IN NAIROBI
}

\section{D.H.O. KWAMANGA, J.A. ODHIAMBO and E.I. AMUKOYE}

\begin{abstract}
Objectives: To determine the prevalence of smoking and investigate factors that may influence smoking behaviour in secondary school students in Nairobi.

Design: Cross-sectional survey in which a self-administered questionnaire was issued to the students.

Setting: Sampled public and private secondary schools in Nairobi.

Participants: All the students in the selected secondary schools were included in the study. Results: Five thousand, three hundred and eleven(74. 1\%) secondary school students were covered. There were 3658 boys and 1653 girls in the study. The mean age was 16.7 years SD \pm 1.48. The study covered $3065(77.3 \%)$ and $2246(70.1 \%)$ of the public and private school students respectively. A total of 1709 (32.2\%) were ever-smokers. The overall rate of eversmoking by gender among the students was $38.6 \%$ of males and $17.9 \%$ of the females. Experimentation with smoking started at five years and regular smoking at 10 years but majority of students $(\mathbf{7 2 . 2 \%})$ started at between age 12 and 16 years. Parents' and teachers' smoking habits influenced initiation of smoking by young children while peer pressure, advertising and type of school influenced older children to smoking. About $67 \%$ of the eversmokers stopped the habit giving various reasons. There was a strong relationship between age of smoking initiation and stoppage. Majority of the students smoked either to enhance their personalities or for stimulation. Most students smoked less than five cigarettes per day. General shops, kiosks and cigarette stalls which sell cigarettes in both packets and single sticks were the main source to students. Students smoked mostly in the evening and at night. Most student smokers were not discouraged by health warnings on the cigarette packets and awareness of the dangers of smoking. Enforceable legislation that would ban advertising and make smoking illegal was the main recommendation from the students.

Conclusions: Smoking is a problem among Kenyan students. The habit starts quite early in life. Peer pressure, advertising, type of school and age influenced smoking among the students. Banning the sale of cigarettes in single sticks is recommended. Anti-smoking campaigners and specially trained school teachers should encourage attitude shaping among school children towards self confidence and adequacy.
\end{abstract}

\section{INTRODUCTION}

Over three million people world wide die prematurely because of cigarette smoking and tobacco consumption annually, one million of whom are from developing countries $(1,2)$. A study in Kenya on cigarette smoking among students found a prevalence rate of $20 \%$ and an average age of onset at 14 years(3). Another study in Kenya among 672 workers at Kenyatta National Hospital, Nairobi, Kenya, found that $365(54.4 \%)$ were regular smokers out of whom $8 \%$ were females(4). Cigarette smoking among African students is reported to be on the rise in Nigeria among adolescent secondary school students where $40 \%$ of the boys and $8-4 \%$ of the girls (5) were regular smokers. A similar study in Uganda found the rates among a similar age group to be $33.4 \%$ and $7 \%$ for males and females respectively(6). Smoking is reported to be as low as $1.1 \%$ and $7.3 \%$ among Tanzanian youth in the rural and urban areas respectively(7). It is much higher $(25.5 \%)$ among the 16 17 year olds in Zimbabwe with a shocking 50\% rate among form one students in the country. Smoking among female students was $0.4 \%$ in Tanzania, $0.7 \%$ in Swaziland and $7.0 \%$ in Zambia. Smoking among female students in Zimbabwe is $6.0 \%$ and $17.3 \%$ among rural and urban private school girls respectively(7).

Smoking is the most important preventable risk factor for diseases, disabilities and death in the world. 
This is because cigarette smoke contains at least 4,700 chemical compounds including 200 known poisons, and 43 cancer causing agents $(2,8)$. Over $30 \%$ of all cancers, $80 \%$ of chronic bronchitis and a large number of emphysema as well as morbidity associated with ischaemic heart disease and peripheral vascular disease are attributable to cigarette smoking. Smoking has also been associated with prenatal morbidity and mortality (2).

Multinational tobacco companies' campaigns are mainly aimed at youth as most tobacco users start young. Children and young adults who know less about the health effects of tobacco, than adults face greater obstacles in making informed choices. It is difficult for most teenagers to comprehend the damage that tobacco use would cause to their health at some distant future, as it is difficult for them to avoid, reduce or stop the use of tobacco once they start smoking it (7).

In recent years, local tobacco companies realised reduction of sales probably as a result of many Kenyan adults becoming aware of smoking related risks. The companies are therefore forced to target another sector of the market in the society and that is the youth. Promotional activities such as "street jams" in Nairobi and Nakuru, "think and win" that involved 400,000 respondents., the "true spirit true taste" and "Beat the Odds" which attracted 2.5 million entries were aimed at the people of all ages but especially the youth and children. Other such promotions, were the launching, of the "Safari King Size Menthol" during which all members of staff of one of the companies went out to merchandise and sell the brand (9). In Nairobi, it is easily observed that children as young as 12 years smoke cigarettes with some of them picking discarded remains of cigarettes and others, buying single stick from the kiosks and vendors. Cigarettes are sold in single sticks which make them easily available to the children. To facilitate gathering of data that would be useful in the control of cigarette smoking in Kenya, this survey was conducted to define the prevalence and pattern of smoking and to investigate factors that may influence smoking behaviour among secondary school students in Nairobi.

\section{MATERIALS AND METHODS}

This was a cross-sectional study carried out among a sample of Nairobi's public and private secondary school students using a WHO standard self-administered questionnaire. Respondents remained anonymous.

Study area: Nairobi is a cosmopolitan city in Kenya with a population of over 2.8 million inhabitants. The Basic Education system here is divided into public and private schools run by the government and private individuals and non-governmental organizations.

Definitions of smoking status: A daily cigarette smoker was defined as a person who smoked at least a cigarette every day within the last one month. A weekly smoker was a person smoking at least one cigarette in seven days in the last four weeks. A current smoker was a person who had smoked at least one cigarette every week for at least the last four weeks. Occasional smoker is a person who smoked less often than once a week or only on special occasions. An ever smoker is a person who had ever smoked a cigarette at any time in his/her life. An ex-smoker is a person who was a regular cigarette smoker, but had stopped more than a month before the date of the interview. A never smoker is a person who had never tried cigarette smoking.

Design and Sampling: This was a cross-sectional survey of smoking habits among secondary school students in the city of Nairobi. Samples of all secondary school students from selected public and private schools were studied.

Cluster sampling was used to select the Secondary schools (both public and private) to be studied. The eight educational divisions in Nairobi province served as the clusters. In each division, simple random sampling was used to select one private and one public secondary school. All the students from the selected schools were included in the study. Sixteen out of sixty eight schools were systematically selected from the study area. All the students in the selected schools were eligible for the study. Each student received a self-administered standard respiratory questionnaire adapted to obtain a personal and smoking history. Additional questions relating to factors that were likely to influence smoking behaviour were included. The Questionnaires were anonymous and distributed publicly to the participants in their classrooms to alley suspicion and fear of identification and intimidation by the teachers. They were pretested in two non-study schools and were filled out by the respondents in the presence of a study facilitator, who first explained confidentiality of the information and procedures for completion of the forms.

Data management: EPI-INFO 6.02 statistical package for data analysis that accounted for stratification and clustering of the students within the schools and types of schools (public or private) was used.

\section{RESULTS}

At the time of the study, a total of 7169 students were attending the sample secondary schools in Nairobi. Of these, 5311 were included in the study. This resulted in a coverage rate of $74.1 \%$. There were no refusals and the 1858 students whose records are missing were absent from school on the survey day, There were almost twice as many boys as girls at $3658(68.1 \%)$ and $1653(31.1 \%)$ in the population studied respectively. Most students were between 15 and 18 years old. Their mean age was 16.7 years $\mathrm{SD} \pm$ 1.5. The age range was similar in the male and female students. There were 3965 students in the public schools, $3065(77.3 \%)$ of whom were included in the study. Private schools registered 3204 students 2246 (70.1\%) of whom participated in the study.

One thousand seven hundred and nine $(32.2 \%)$ of the total population of the students had ever smoked cigarettes at one time. Of this, $82.7 \%$ were males and $17.3 \%$ females. The overall rate of ever-smoking among the study population by gender was $38.7 \%$ among males and $17.7 \%$ among females.

Mean age of male smokers was 16.8 years, SD 1.45 and female smokers was 17.1 years, $\mathrm{SD} \pm 1.4$. Smoking in schools increased with age from 14 years regardless of gender as indicated by upwards linear trend (Figure 1) $\left(\mathrm{X}^{2}\right.$ for linear trend $=74.6 \mathrm{p}<0.001$ ). 
Figure 1

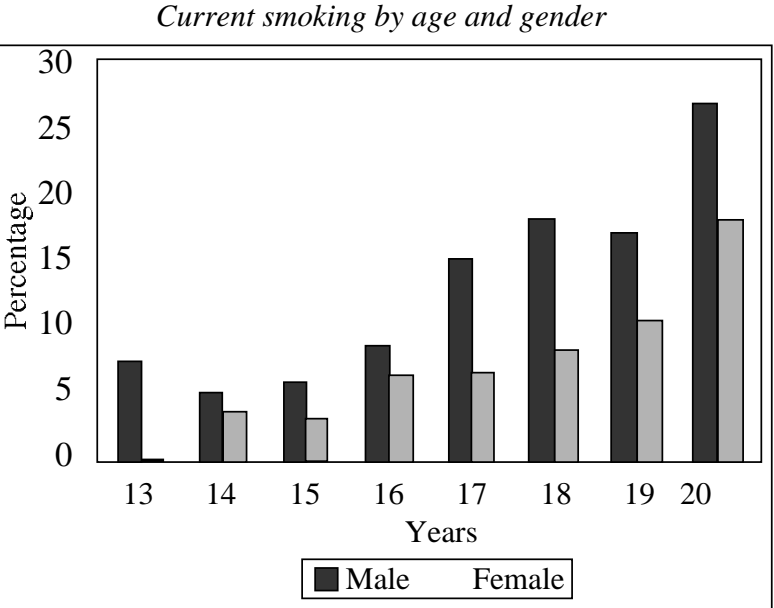

At the time of the study, a total of $1152(67.4 \%)$ out of the 1709 smokers reported to have stopped smoking. The total number of current smokers was therefore 557 (32.6\% of ever-smokers). The rate of current smoking among the total study population was $10.5 \%$. A total of $12.4 \%$ of male students and $6.4 \%$ of female students were current smokers. There is no significant difference in smoking prevalence between male and female students by age as shown in Figure 1. $\left(X^{2}=4.76 ; p=0.69\right)$.

\section{Figure 2}

Age smoking started by gender

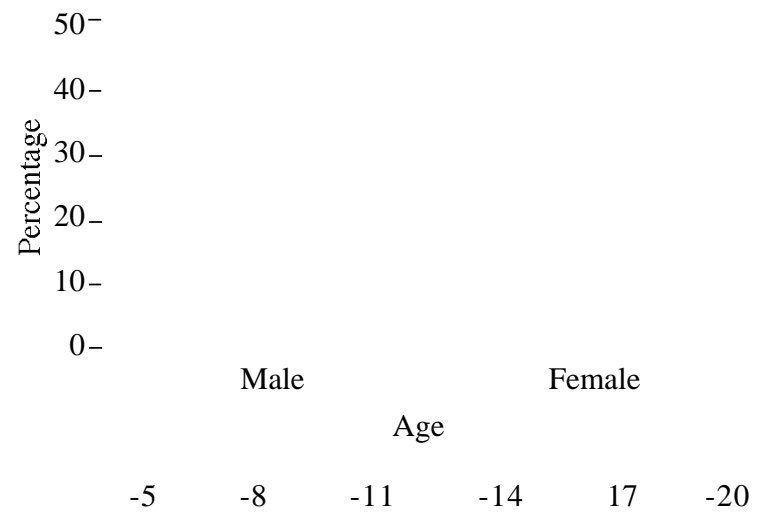

Students started to experiment with smoking at the age of five years although regular smoking started at age 10 years but majority of the students $(72.2 \%)$ started at age 12 16 years. Only $2.2 \%$ of the students started to smoke after the age of 17 years (Figure 2). The students who went through age 17 years before starting to smoke were very unlikely to smoke by the age of 20 years. There was no significant difference in the age of smoking initiation between the male and female students $\left(X^{2}=20.3 ; p=0.12\right)$

The age of smoking initiation was determined by the presence of a smoker either at home or in school. Most of the students, who recall trying smoking for the first time at nursery school age (5 years), indicated that they had their teachers smoking in the school. The rest in this age group had smoking parents. Those who started smoking at the ages 6-11 years mostly had their friends $(39.0 \%)$ teachers $(26.80 \%)$ and parents $(24.4 \%)$ as smokers. The $12-20$ year old smoking initiators had smoking friends $(58.9 \%)$, teachers (24.7\%) and parents (12.7\%) (Figure 3).

Figure 3

Presence of smoker at initiation of smoking by age group

Many students continued smoking under the influence of peer pressure that is encouraged by colourful and persistent advertising both in print and electronic media and promotions and sponsorship of sporting activities. Cultural and social events at Kenya National Agricultural Shows played major roles (Figure 4). There was a statistically significant difference in smoking rates between the private and public secondary schools. While only $7.3 \%$ of the students in public schools smoked cigarettes, $14.1 \%$ or almost twice as many of the students from the private schools smoked $\mathrm{OR}=2.08(1.72: 2.53 .95 \% \mathrm{CL}) \mathrm{X}^{2}=59.3 \mathrm{p}<0.001$.

Figure 4

Influence for continuing smoking
There was no difference between the private and public schools in terms of frequency of current smoking among the students. 
Most students, who had ever used tobacco, smoked less than five cigarettes per day (70.\%). This was followed by $16.1 \%$ of them who smoked 6-10 cigarettes a day. This rate of smoking is similar in male and female students at $70.4 \%$ and $68.6 \%$ respectively with $\mathrm{OR}=0.82(0.43 ; 1.59)$ $95 \%$ CL (Table 1).

\section{Table 1}

Number of cigarettes smoked daily by gender

\begin{tabular}{lcccccc}
\hline Number & Males & $\%$ & Females & $\%$ & Total & $\%$ \\
\hline$<5$ & 490 & 70.4 & 107 & 68.6 & 597 & 70.1 \\
$6-10$ & 116 & 16.7 & 21 & 13.5 & 137 & 16.1 \\
$11-20$ & 46 & 6.6 & 14 & 9.0 & 60 & 7.0 \\
$21-30$ & 26 & 3.7 & 10 & 6.4 & 36 & 4.2 \\
$31-40$ & 11 & 1.6 & 3 & 1.9 & 14 & 1.7 \\
$>40$ & 7 & 1.0 & 1 & 0.6 & 8 & 0.9 \\
\hline TOTAL & 696 & 100 & 156 & 100 & 852 & 1000 \\
\hline
\end{tabular}

Cigarettes were mostly obtained from general shops (50.1.\%) and kiosks (27.0\%) where they were conveniently sold in single sticks to those who did not have enough money to spend on a full packet. Majority of the smoking students fell under this category.

There were more students $(26.6 \%)$ smoking cigarettes in the evenings on their way from school in the company of their friends and at home in their rooms at night (39.9\%) than at any other time. A few of them smoked during lunch break.

A total of 1709 ever smoking students responded to the question of stopping to smoke. Of these, $1152(67.4 \%)$ had stopped smoking leaving a total of $557(32.6 \%)$ as regular smokers.

Forty two and half percent of the students indicated that they had stopped smoking due to health awareness and medical reasons which included cough (13.3\%), fast heartbeat $(7 \%)$ and chest pain $(14.4 \%)$. In addition to these, $36 \%$ of them gave no specific reasons for the stoppage. The information was specifically given by older students aged 18-20 years. The other reasons were social, religious and family in the order of importance. About $6 \%$ of them reported cigarette smoking as not enjoyable to them.

Being aware of health warnings on the cigarette packs did not play any significant role in the cessation of smoking. Some students who had seen the health warnings on the packs stated that the writings were too small to be seen easily. Others said that they only buy single cigarettes and have never seen any such writings on them. However, the students who stopped smoking and those who continued were equally aware of the dangers of smoking cigarettes. Many students who started smoking to relieve themselves of pressure $(24 \%)$ and get pleasure (22\%) stopped smoking. Only $8.1 \%$ of those who smoked out of habit and $13.2 \%$ of the addicted smokers stopped smoking.

There was significant relationship between the number of cigarettes smoked in a day and stopping smoking. Among the students who stopped smoking, 79.4\% smoked less than five cigarettes. It is observed here that the more a student smoked the less likely he/she was to stop. $\mathrm{OR}=0.22$ (0.19; 0.26) 95\% CL., $\mathrm{X}^{2}=39.56 \mathrm{P}<0.001$.

The age at which the students started to smoke was also related to smoking cessation. The students who started smoking at a younger age of about 17 years had a cessation rate of $54.9 \%$ while those who started at around the age of 18 years had a rate of $13.2 \%$, This means that over $45 \%$ of the students who stated smoking at a young age of about 17 years continued smoking to the time of the study. Strong relationship exists between the frequency of smoking and stopping the habit as more occasional smokers (73.5\%) than regular smokers (17.6\%) stopped smoking. OR=2.99 (1.30; 7.06) 95\%CL., $\mathrm{X}^{2}=7.20 \mathrm{P}<0.007$. Although fewer female than male students smoked cigarettes, more males $(26.3 \%)$ than females $(11.5 \%)$ stopped smoking.

Fifty two percent of the students who had never smoked cigarettes gave health implications of smoking as the reason. Religious reasons accounted for $26.2 \%$ and $15.7 \%$ of them did not like the smell and smoking behaviour(20) .

The most common recommendation of those who had stopped smoking was to enact a law making smoking illegal and ban its use completely. Others (19\%) felt that all cigarette advertising should be banned and still others (19\%) suggested that anti-smoking health education campaigns be started in schools, $18 \%$ recommended price increase and $5 \%$ of them appealed for a smoking ban in public places.

Figure 5

Students recommendations by gender

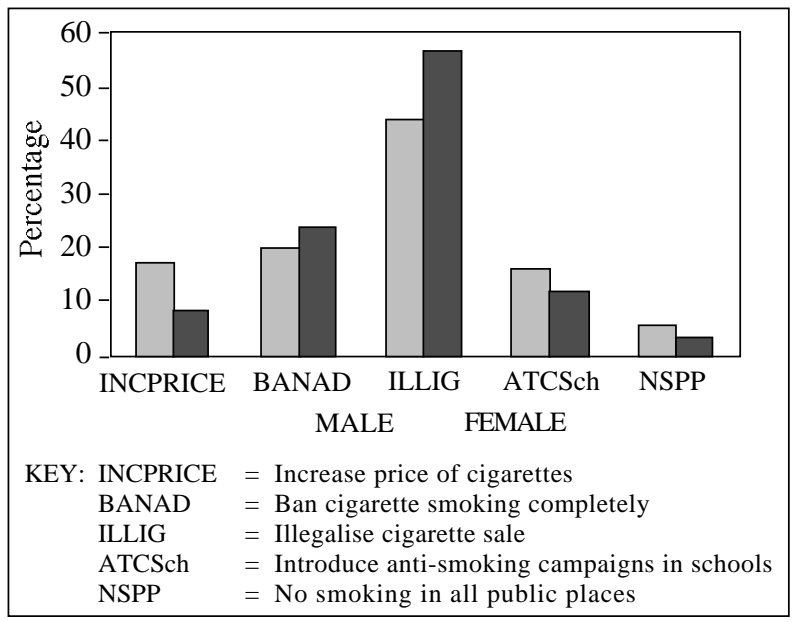

The observations were similar among both males and females in the whole student population. Most students of all ages, both smokers and non-smokers, recommended 
that cigarette smoking be made illegal, especially for those below age 18 years, advertising, product promotions and sponsorship be banned, cigarette prices be increased, anti smoking education be introduced in the primary and secondary school syllabuses and all public places to be tobacco-free areas ( Figure 5).

\section{DISCUSSION}

Prevalence of smoking and factors associated with secondary school students smoking although well studied in developed countries, have not been fully explored not only in Nairobi but also in Kenya as a whole. This representative survey of secondary school students in Nairobi investigated the prevalence of smoking and the possible risk factors that influence it.

Although no biological marker was used to validate the smoking status reported by the students, the likelihood of under reporting by smokers was minimised by the assurance of confidentiality of the information gathered from the survey. The confidentiality was confirmed by keeping the teachers out of the interview rooms and allowing the questionnaires to be collected only by the research team.

The students participated voluntarily in the survey as such there were no refusals. Prevalence rate of smoking among the students was spread through the classes with form one students having the lowest rate and the form fours the highest in both public and private schools. Although smoking among female students is significantly lower than their male colleagues in Kenya, as compared to developed countries, it is quite high compared to other African countries with similar traditional, cultural and social norms that discourage cigarette smoking habits among females (7).

Smoking among students started very early in life (five years). It came out that this is due to the smoking habit of their parents at home and teachers at schools. Many students are more likely to smoke if they lived in a family where at least a member of the family smoked or likely to provide cigarettes to them.

The age of starting regular smoking in Kenya seemed to have decreased from 18-24 years, as reported by a study on primary school teachers to 12-16 years reported in the current study(10).

Evidence of an influential role played by teachers is significant. It is therefore concluded that teachers and parents are both well placed to influencing anti-smoking campaign messages by not smoking themselves. This action would help in reducing both active and passive smoking at school as well as at home thus reducing the risk of smoking related health hazards. This finding confirms another study's finding that smoking habit of adolescents is correlated with smoking status of their families. However it was observed that any student who does not start smoking by age 17 years is very unlikely to smoke by the age of 20 years. It is therefore recommended that controlling cigarette smoking should start with the parents at home who should not only show their young children bad example by smoking but also guide them on what they watch on televisions and listen to in the radios. School teachers especially in nursery and primary schools should also take greater interest in cigarette smoking control in schools. A number of students stopped smoking giving health reasons. This group of students may be important change agents to other students if necessary assistance is given to them. Awareness of the health warning on the cigarette packets did not play any significant role in stopping smoking since almost all the students, those who stopped and those who were still smoking, were well aware of the health warning on the cigarette packets. However, they claimed that the writings on the packets were invisible and need to be equally as prominent as the labels on the packets. Peer pressure and advertising stood out as the main risk factors for continuing to smoke. Making smoking and sale of cigarettes to those below 18 years illegal and totally banning advertising, sponsorship of sporting and cultural events by tobacco industry was recommended by majority of the students. Although it may not be practical at the moment to make smoking unlawful, stricter control of the use of cigarettes and effective banning of advertising as recommended by the students may save lives of many unwitting active and environmental smokers. The students also recommended increased taxes and prices of cigarettes. The increased taxes may be used to sponsor the same events the tobacco industry is sponsoring currently.

The study found that majority of the students smoked to enhance their personalities and for stimulation. Most students smoked less than five cigarettes per day. This was probably due to the cost and time of smoking or both. General shops, kiosks and cigarette stalls which sell cigarettes in both packets and single sticks are the main sources of cigarettes to students most of whom cannot afford to buy cigarettes in packets. If selling of cigarettes in single sticks is effectively banned by law, many students would be discouraged from smoking.

Since there is no difference between smokers and non-smokers in terms of knowledge about the danger of smoking, disseminating knowledge to the students alone is not enough to dissuade them from smoking. Antismoking campaigners should shift their strategies from punitive prohibitions to encouraging attitude shaping among students. Students and other adolescents would only be persuaded from smoking if the attitude shaping started in their primary school age-group. Specially trained teachers should be available to guide the children towards self confidence and inculcate the feeling of self-control and adequacy without the assistance of cigarettes and other personality enhancing drugs. A comparison of these results and those of studies from other countries show that adolescent smoking in this country is similar to other countries in Africa where tobacco control measures are effectively being enforced. Anti-smoking legislation that will control sale and use of tobacco and tobacco products 
in addition to effective health education and advocacy campaigns are urgently required.

\section{ACKNOWLEDGEMENTS}

This work was carried out with support from International Union against Tuberculosis and Lung Diseases and Kenya Medical Research Institute (KEMRI) and is published with the approval and permission of the Director KEMRI. Our sincere gratitude goes to the Director of Education for permission and support for the survey. To the head teachers, the teachers and students and the staff of CRDR for their co-operation and support.

\section{REFERENCES}

1. WHO Workshop on smoking and health issues in developing countries. Colombo. 1981 pp18-20.

2. IUATLD News Bulletin on Tobacco and Health Report October; 15-16 1992 Paris, France Vol.6, 1993.
3. Lore, W. Smoking habits in Kenya I. A preliminary study involving University of Nairobi Medical Students. East. Afr. Med. J. 1987; 64:248-252.

4. Lore, W. and Lwenya, R. A follow up study involving personnel working at Kenyatta National Hospital Nairobi. East. Afr. Med. J. 1988; 65:71-80.

5. Elegbeleye, O.O. and Femi-Pearse, D. Incidence and variables contributing to onset of cigarette smoking among secondary school students and medical students in Lagos Nigeria. Brit. J. Prev. Soc. Med. 1976; 30:60-70.

6. Arya, O.P. and Bennett, F.J. Smoking among University Students in Uganda, an analysis on Prevalence and Attitudes. East. Afr. Med. J. 1970; 47:18-26.

7. Guthrie, T., Shung-King, M., Stelyn, K. and Mathambo, V. Children Tobacco in South Africa. A literature review of health effects, Youth smoking pattern and tobacco control measures. Cape Town November 2000:45-55.

8. Winckstrom, B.O. Cigarette Marketing and the Third World. Gothenburg, Sweden: University of Gothenburg, 1974.

9. British American Tobacco Kenya Limited - Annual Review 2000; 1-15.

10. Kwamanga D.H.O., Odhiambo, J.O. and Gichecha, C. Tobacco consumption among primary school teachers in Nairobi. East. Afr. Med J. 2001; 78:119-123.

\section{EAMJ INTERNET ADDRESS}

The East African Medical J ournal is now available online as well as in print. Subscribers and readers interested in viewing the Internet version may access it using the following address: http:/ / www.biolineorg.br

The Online version is distributed by the non-profit service; Bioline Publications, a South/North partnership whose aim is to facilitate global access to bioscience and medical research publications, with emphasis on journals published in the developing world.

Subscription to the online version may be made by completing the Registration form available from the Bioline home page (http:/ / www.biolineorg.br). Readers may take out an annual subscription or purchase single documents. Abstracts are available without registration and free of charge. 